\title{
Evaluation and prediction of the effect of load frequency on the wear properties of pre-cracked nylon 66
}

\author{
A. ABDELBARY* ${ }^{*}$ M. N. ABOUELWAFA, I. M. EL FAHHAM \\ Mechanical Engineering Department, Faculty of Engineering, Alexandria University, Alexandria, Egypt \\ Received: 14 October 2013 / Revised: 28 December 2013 / Accepted: 20 February 2014 \\ (C) The author(s) 2014. This article is published with open access at Springerlink.com
}

\begin{abstract}
Nylon 66 has been widely used for numerous mechanical applications but its sliding wear mechanisms are not fully understood. In particular, limited attention has been paid to the generation of fatigue surface cracks under constant and cyclic load conditions. The present work focuses on the effect of load frequency on the wear behavior of a polymer with surface defects in dry sliding conditions. The defects were imposed vertical deep cracks perpendicular to the direction of sliding. Wear studies were conducted against a steel counterface at constant loads, and in cyclic loads at different frequencies. Artificial neural network (ANN) models were examined to identify one that optimally simulates wear under the applied load parameters.

Surface cracks were found to have a remarkable adverse effect on the wear behavior of the polymer. The wear rates were influenced by the number of cracks as well as the type of applied load. Furthermore, results suggest that the presence of surface cracks is attributable to the section B wear regime. Finally, acceptable predicted wear rate values were obtained by introducing the ANN wear model.
\end{abstract}

Keywords: nylon; wear; surface defects; wear model

\section{Introduction}

Nylon 66, an important engineering polyamide, has been established as a valuable material in gears and bearing applications due to its superior wear resistance and self-lubricating characteristic [1]. These excellent properties result from the presence of hydrogen bonds in the molecular chains of the polyamides. Recently, the tribological behavior of nylon has been widely investigated [2-4].

Surface fatigue wear (SFW) is one of the major contributors to overall wear phenomena, occurring in polymer/metal tribosystems especially during dry sliding conditions. SFW in polymers likely results from repeated stress cycles applied to materials associated with asperity interactions [2]. In contact sliding, many surface and subsurface cracks are initiated that

* Corresponding author: A. ABDELBARY.

E-mail: Elbary1972@yahoo.com (A. ABDELBARY), Ibrahim.elfahham@alexu.edu.eg (I. M. EL FAHHAM) propagate deeply into the substrate or link up with other cracks until eventually one crack is large enough to break from the bulk, causing pitting and spalling [3]. Microscopic investigation of a nylon 66 worn surface has shown a number of transverse vertical cracks, suggesting that surface cracks play an important role in SFW. The nature and number of surface crack initiation sites depends on the type of loading exerted on the surface and the sliding conditions $[2,4]$.

The effect of cyclic loading on the sliding wear of polymers has also been studied by many researchers [5-8]. It has been reported that wear factors under dynamic loading conditions are about 30\% larger than under a constant load of the same magnitude. In cyclic loading, the loading-unloading cycles generate subsurface stress regions that increase the tendency for surface and subsurface cracks to be initiated. Propagation of these microcracks may well accelerate the failure and removal of material from the highly strained polymer peaks, and generally increase polymer wear [9]. 
Furber et al. [10] and Atkinson et al. [11] introduced a third wear regime referred to as section $\mathrm{B}$ wear. They observed a marked increase $(10 \%-30 \%)$ in the wear rate after a certain sliding distance on a steady-state wear curve and suggested that section B is surface fatigue wear that takes place after a number of cycles to failure proportional to the sliding distance. Evidence of transverse cracks in the polymer surface suggested the possibility of a fatiguing process. A similar observation of an increasing wear rate after prolonged running was also reported by Anderson et al. [12].

Insufficient details as to how the SFW mechanisms initiate and develop with time, and the lack of explanations about the factors that may govern these mechanisms, prevent their comprehensive study.

The modeling of wear properties generally involves the development of mathematical models derived from experimental data. A number of these models have been derived to simulate the wear behavior of materials under limited conditions. However, no model has been developed to express the general wear properties of polymers, especially under cyclic loading conditions. Recently, artificial neural networks (ANNs) have emerged as good candidates for mathematical wear models due to their capabilities in nonlinear behavior, learning from experimental data, and generalization [13].

Hutching's group [14] and Jones et al. [15] presented pioneering investigations of ANN techniques for predicting tribological parameters. Subsequently, several researchers [16-20] investigated the potential of ANNs to predict and analyze wear behavior under various parameters. Lada et al. [20] demonstrated that it is possible to develop an ANN model that is able to learn from examples presented to it and to construct a proper fitting function that correctly reproduces not only the characteristic tribological properties for these examples, but is also able to interpolate correctly for unseen cases from the same knowledge domain.

Despite these encouraging developments, the application of ANNs in the field of tribology is still in the very early stages, which means that the investigations of their potential implementation in various material research areas and for improving our predictive capabilities require further research.

The present study investigates the influence of load frequency on the wear of a nylon 66 specimen with a pre-existing defect on its rubbing surface. Additional tests were designed to explore the relationship between SFW and the section B wear regime. Polymer wear pins were tested against a steel counterface using a reciprocating test rig in dry sliding conditions. Constant load tests were conducted at two loads, and in cyclic load tests the polymers were tested at two frequency levels. The imposed defects consisted of vertical deep cracks perpendicular to the direction of sliding. All imposed cracks were generated with a sharp razor. Finally, the ANN wear model was applied, trained, and tested based on experimental data obtained from current and previous studies [21] in order to predict the wear rates of the polymer under conditions such as fluctuating loads at different frequencies and in the presence of surface cracks.

\section{Apparatus and materials}

The current work was carried out on a dual sixstation linear reciprocating pin-on-plate tribometer as shown in Fig. 1(a). The rig was constructed and used by the authors to investigate the effect of cyclic load parameters (mean, maximum, and frequency of cyclic load) on polymer wear, and is described fully elsewhere [8]. The cyclic loading system performed wear tests under fluctuating loading circumstances generated by the rotation of an array of 6-sine cams driven by an external motor. When the cam rotates, the cam follower transmits the displacement to a compression spring that generates a sine curve force at the test pin holder, as shown in Fig. 1(b). The tribometer provides a reciprocating motion to the matting counterface at a linear constant speed of $0.25 \mathrm{~m} / \mathrm{s}$. Constant and cyclic loading systems were mounted on the tribometer desktop, each of them acting on one half of the carriage.

The wear specimens were all machined from a 14-mm solid bar of nylon 66 manufactured by Rochling Plastics, USA. The pins were machined into rod-shaped projections $8 \mathrm{~mm}$ in diameter from the main body of the pin as shown in Fig. 2(a). The typical $2.5 \mathrm{~mm}$-imposed vertical cracks were generated on the polymer surface with a sharp razor installed on a special device suggested elsewhere [22, 23]. The orientation of the imposed crack with respect to the 

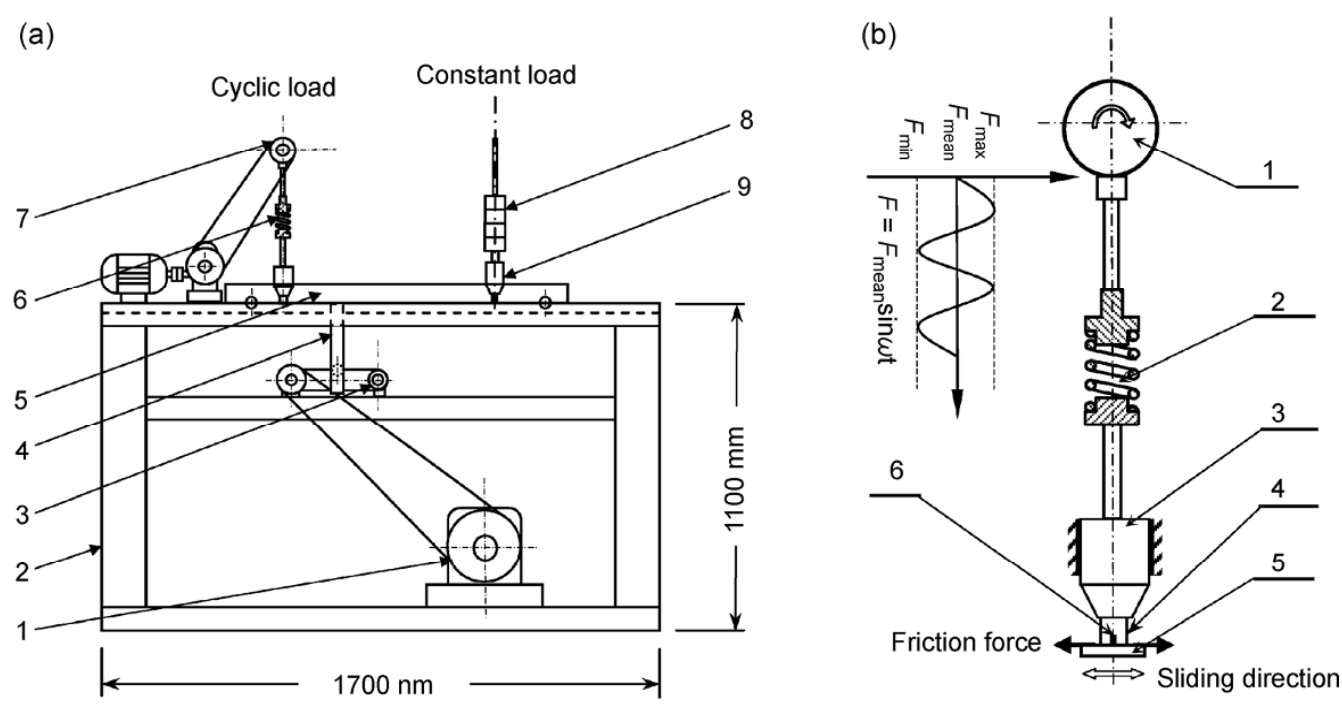

Fig. 1 (a) Tribometer: (1) motor; (2) machine frame; (3) chain drive mechanism; (4) U-beam guide; (5) reciprocating carriage; (6) spring; (7) eccentric cam; (8) dead weights; (9) pin holder. (b) Cyclic load system: (1) eccentric cam; (2) compression spring (3) pin holder; (4) polymer specimen; (5) steel counterface; (6) imposed crack.

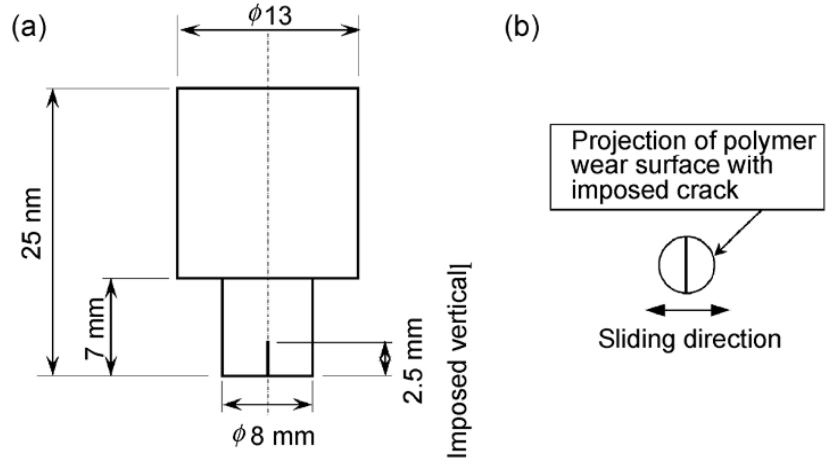

Fig. 2 (a) Wear pin geometry. (b) Crack orientation with respect to sliding direction.

sliding direction is shown in Fig. 2(b). The reciprocating counterface plates with dimensions of $330 \mathrm{~mm} \times$ $30 \mathrm{~mm} \times 3 \mathrm{~mm}$ were machined from steel AISI 1050 . All plates were prepared by surface grinding to provide a surface with a center line average $\left(R_{\mathrm{a}}\right)$ value of $0.2-0.4 \mu \mathrm{m}$. The grinding direction is parallel to the sliding direction.

\section{Experimental work}

In order to study the wear behavior of nylon 66, two sets of tests were performed. First, constant load tests were conducted to investigate the effect of an imposed crack on the wear rate at two loads $(F=90 \mathrm{~N}$ and
$135 \mathrm{~N})$. In cyclic load tests, pre-cracked polymer was examined at $F_{\text {mean }}=90 \mathrm{~N}$ and the effect of two frequencies ( $f=0.25 \mathrm{~Hz}$ and $1.50 \mathrm{~Hz}$ ) was considered. The influence of the number of surface imperfections was investigated in tests 3 and 9 by using polymer specimens with three imposed cracks. Tests 6 and 12 were designed to explore the relationship between surface cracks and the section B wear regime at constant and cyclic loads. The tests began using an uncracked pin; subsequently, a surface crack was imposed after $80 \mathrm{~km}$ sliding distance and tests were run again for another $40 \mathrm{~km}$ of sliding. Optical microscopes and photography were employed to examine the polymer worn surface as well as the metallic counterface. The wear rates were calculated according to the relationship:

$$
\mathrm{WR}=V / X \quad\left(\mathrm{~mm}^{3} \cdot \mathrm{m}^{-1}\right)
$$

\section{Results}

\subsection{Wear rates}

Tables 1 and 2 present a summary of the wear results. In constant load tests, the wear rates were greatly affected by the existence of surface cracks. The wear rates increased from $13.3 \times 10^{-4} \mathrm{~mm}^{3} \cdot \mathrm{m}^{-1}$ (test 1 ) to $14.8 \times$ $10^{-4} \mathrm{~mm}^{3} \cdot \mathrm{m}^{-1}$ (test 2) and from $18.1 \times 10^{-4} \mathrm{~mm}^{3} \cdot \mathrm{m}^{-1}$ (test 4) to $30.7 \times 10^{-4} \mathrm{~mm}^{3} \cdot \mathrm{m}^{-1}$ (test 5) with a single 
Table 1 Results of constant load wear tests.

\begin{tabular}{ccccccc}
\hline Test & $\begin{array}{c}\text { Applied force, } \\
F(\mathrm{~N})\end{array}$ & $\begin{array}{c}\text { Imposed } \\
\text { surface cracks }\end{array}$ & $\begin{array}{c}\text { Total sliding } \\
\text { distance, } X(\mathrm{~km})\end{array}$ & $\begin{array}{c}\text { Wear rate of sec. A, } \\
\mathrm{WR}\left(\times 10^{-4} \mathrm{~mm}^{3} \cdot \mathrm{m}^{-1}\right)\end{array}$ & $\begin{array}{c}\text { Sliding distance at } \\
\text { onset of sec. } \mathrm{B}(\mathrm{km})\end{array}$ & $\begin{array}{c}\text { Wear rate of sec. B, } \\
\mathrm{WR}\left(\times 10^{-4} \mathrm{~mm}^{3} \cdot \mathrm{m}^{-1}\right)\end{array}$ \\
\hline 1 & 90 & - & 110 & 13.3 & - & - \\
2 & 90 & 1 & 80 & 14.8 & - & - \\
3 & 90 & 3 & 80 & 25.2 & - & - \\
4 & 135 & - & 90 & 18.1 & - & - \\
5 & 135 & 1 & 90 & 30.7 & 12.7 & 80 \\
6
\end{tabular}

Table 2 Results of cyclic load wear tests $\left(F_{\text {mean }}=90 \mathrm{~N}, F_{\min } / F_{\max }=0.06\right)$.

\begin{tabular}{ccccccc}
\hline Test & $\begin{array}{c}\text { Cyclic frequency, } \\
f(\mathrm{~Hz})\end{array}$ & $\begin{array}{c}\text { Imposed } \\
\text { surface cracks }\end{array}$ & $\begin{array}{c}\text { Total sliding } \\
\text { distance, } X(\mathrm{~km})\end{array}$ & $\begin{array}{c}\text { Wear rate of sec. A, } \\
\mathrm{WR}\left(\times 10^{-4} \mathrm{~mm}^{3} \cdot \mathrm{m}^{-1}\right)\end{array}$ & $\begin{array}{c}\text { Sliding distance at } \\
\text { onset of sec. } \mathrm{B}(\mathrm{km})\end{array}$ & $\begin{array}{c}\text { Wear rate of sec. B, } \\
\mathrm{WR}\left(\times 10^{-4} \mathrm{~mm}^{3} \cdot \mathrm{m}^{-1}\right)\end{array}$ \\
\hline 7 & 0.25 & - & 80 & 13.7 & - & - \\
8 & 0.25 & 1 & 80 & 21.8 & - & - \\
9 & 0.25 & 3 & 80 & 29.7 & - & - \\
10 & 1.50 & - & 100 & 15.8 & - & - \\
11 & 1.50 & 1 & 80 & 30.1 & 25.1 & - \\
12 & 0.25 & 1 & 125 & & 27.6 \\
\hline
\end{tabular}

imposed crack. Moreover, the amount the wear rates increased, due to the imposed cracks, was highly affected by the increase in the applied constant loads, as shown in Fig. 3.

However, under a cyclic load at $F_{\text {mean }}=90 \mathrm{~N}$, the wear behavior of the nylon showed a similar trend to

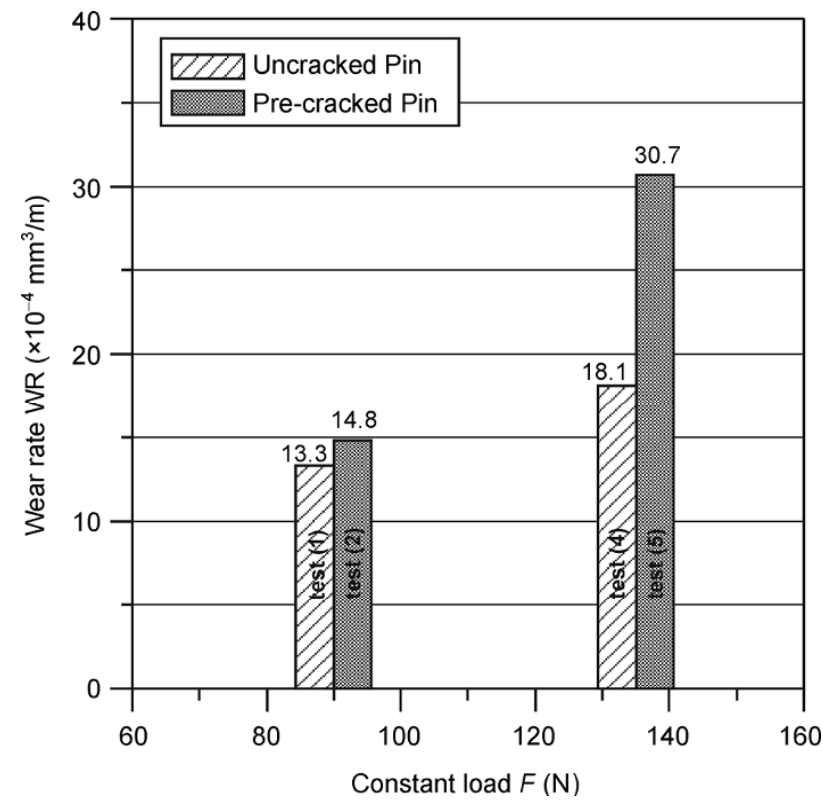

Fig. 3 Effect of imposed surface crack on the wear rate, constant load. those at constant loads, as reported in Table 2. Results indicate that the wear rates of the uncracked specimens, tests 7 and 10, increased from $13.7 \times 10^{-4} \mathrm{~mm}^{3} \cdot \mathrm{m}^{-1}$ to $15.8 \times 10^{-4} \mathrm{~mm}^{3} \cdot \mathrm{m}^{-1}$ (about $15.3 \%$ ) as the load frequency increased from $0.25 \mathrm{~Hz}$ to $1.50 \mathrm{~Hz}$, respectively. The same trend was detected for pre-cracked specimens, in tests 8 and 11, where the wear rates increased from $21.8 \times 10^{-4} \mathrm{~mm}^{3} \cdot \mathrm{m}^{-1}$ to $30.1 \times 10^{-4} \mathrm{~mm}^{3} \cdot \mathrm{m}^{-1}$ (about $38 \%$ ), respectively, as illustrated in Fig. 4 .

The effect of multiple surface cracks on the wear resistance under constant and cyclic loads was considered in tests 3 and 9, respectively. Specimens with three imposed surface cracks were tested at $90 \mathrm{~N}$ applied load. Compared to the wear rates of uncracked pins in tests 1 and 7, a dramatic increase in wear rates of about $90 \%$ to $117 \%$ was obtained due to the multiple surface defects.

Tests 6 and 12 were conducted to investigate the effect of a single transverse crack on the wear rate in a steady state regime. Both tests, at first, started with an uncracked pin, and after $80 \mathrm{~km}$ of sliding distance, a surface crack was made, after which the test continued for another $40-\mathrm{km}$ sliding distance. Plots of volume loss due to wear versus sliding distance with all points marked for these tests are presented in Figs. 5 and 6, 


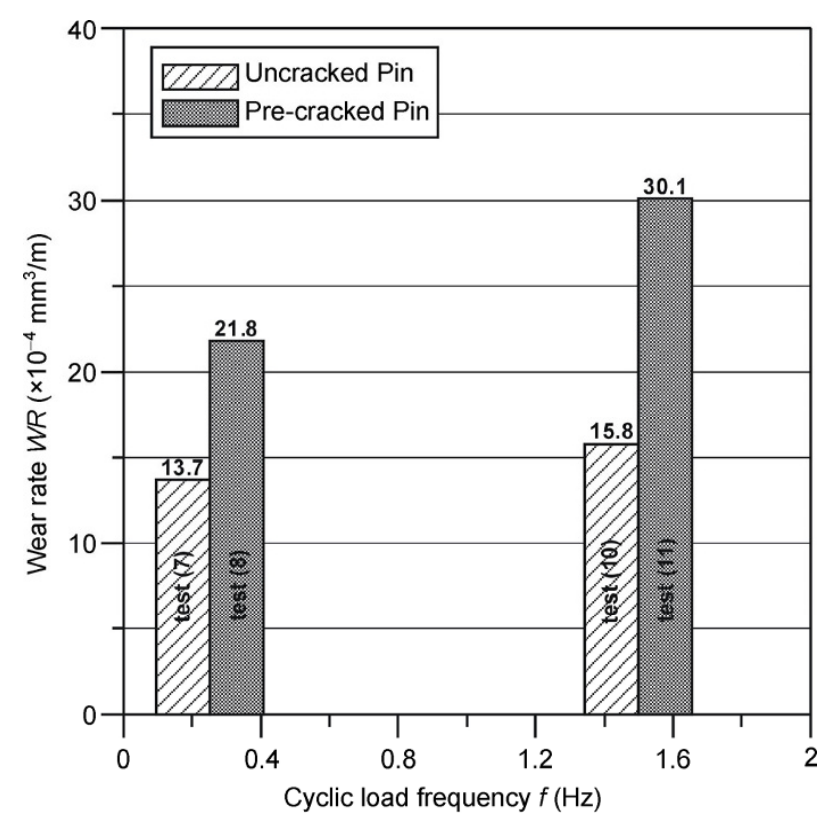

Fig. 4 Effect of imposed surface crack on the wear rate, cyclic load at $F_{\text {mean }}=90 \mathrm{~N}$.

respectively. The wear graphs exhibit two straight line regions, designated as sections A and B. Their slopes were calculated by the least squares method and wear rates determined for each section are given in Tables 1 and 2. One surprising observation was that section $\mathrm{B}$ wear began after $80 \mathrm{~km}$ of sliding, i.e., just after the formation of the surface crack. Although the increase in wear rates was only about $15 \%$, this is still a significant increase since there were no changes in any of the other test conditions.

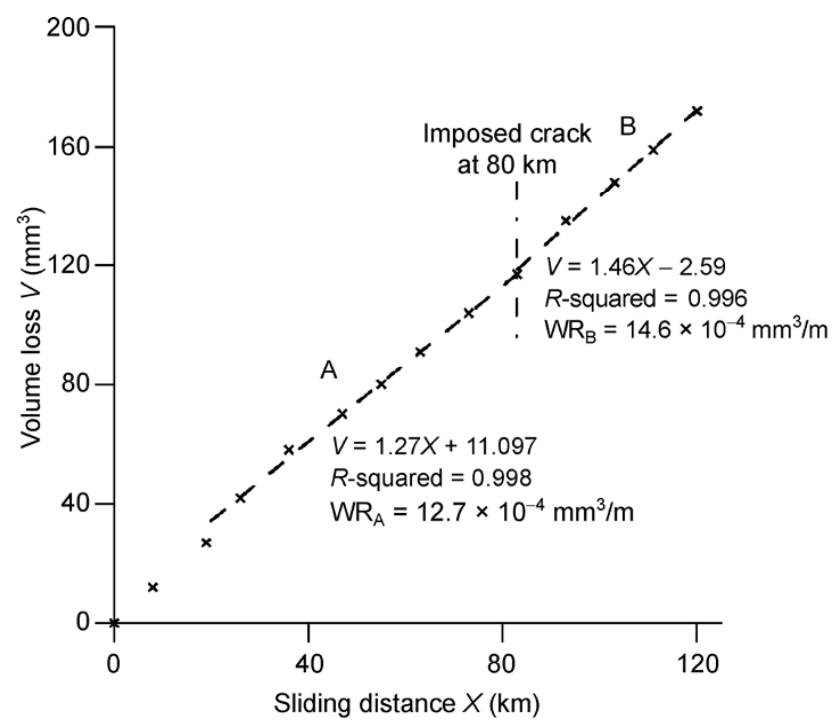

Fig. 5 Wear plot for Test 6, surface crack was imposed after $80 \mathrm{~km}$ of siding.

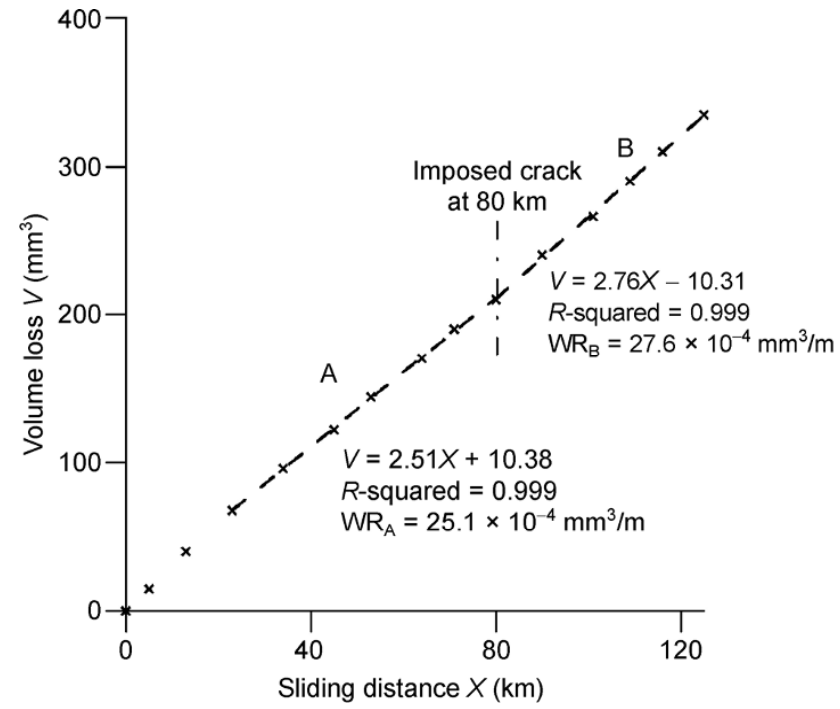

Fig. 6 Wear plot for Test 12, surface crack was imposed after $80 \mathrm{~km}$ of siding.

\subsection{Microscopic observations}

Uncracked specimens. Features observed on the polymer worn surfaces were common to all uncracked pins examined; test 10 , carried out with a cyclic load, can be taken as representative. On the wear surface generated after $60 \mathrm{~km}$ of sliding, as shown in Fig. 7(a), apparent wear grooves parallel to the sliding direction formed on the worn surface of the nylon 66 , and these valleys were present at all stages. The appearance of wear grooves can be attributed to the banded transfer of polymer to the counterface; the grooves appear opposite the bands of transfer. The formation and build-up of polymer transfer film on the steel counterface was examined. Figure $7(b)$ shows a uniform and continuous transfer film on the steel counterpart surface after $20 \mathrm{~km}$ of sliding. Polymer transfer is observed to be heaviest at the center of the track and decreases towards the edges. This is attributed to the circular shape of the specimen where the mid-track position comes into contact with a greater area of the wear pin at each pass. The track width of the transfer film was about $4 \mathrm{~mm}$ in the beginning and then became wider as the test progressed, eventually producing a fairly uniform appearance. These observations agree with previously reported data results from the same polymer sliding against a stainless steel counterface [10].

(a) One surface crack. Figures 8(a) and 9 illustrate the typical appearance of nylon 66 worn surfaces with a 
(a)

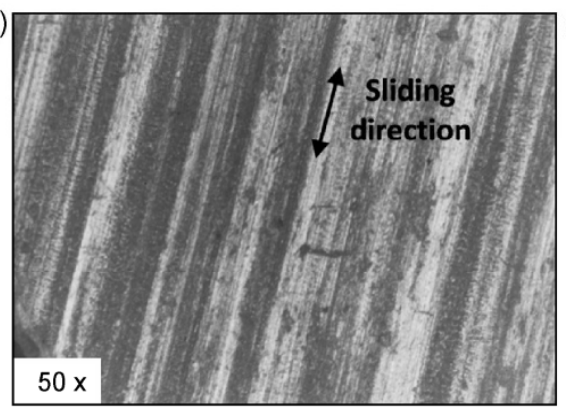

(b)

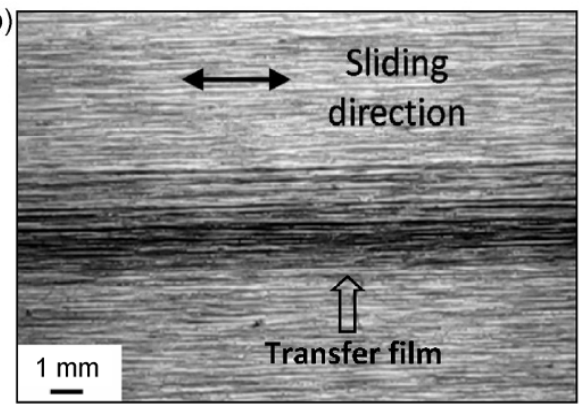

Fig. 7 Test 10 optical micrograph of: (a) wear pin surface after $60 \mathrm{~km}$ sliding showing wear grooves parallel to the sliding direction and (b) steel counterface showing transfer film formed after $20 \mathrm{~km}$ sliding.

(a)

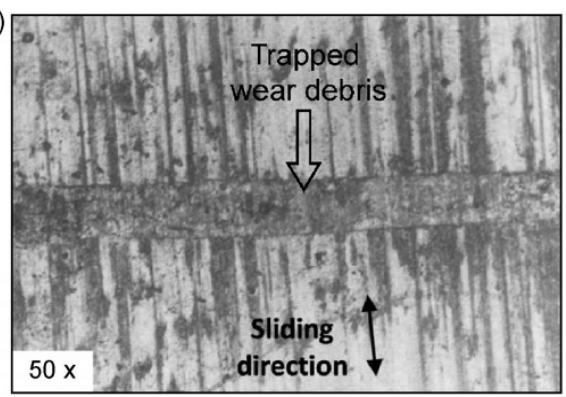

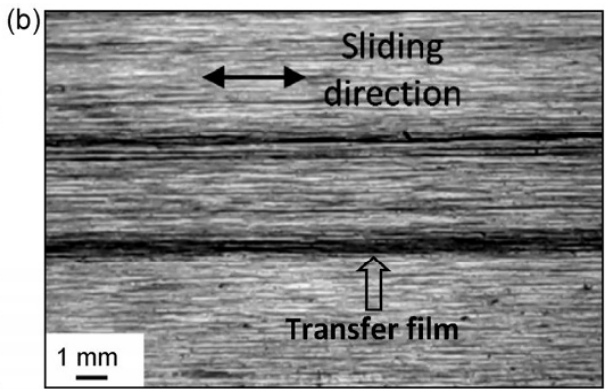

Fig. 8 Optical micrographs of test 11 after $20 \mathrm{~km}$ sliding showing: (a) wear pin surface with trapped wear debris inside the crack mouth and (b) steel counterface with transfer film formed.

single imposed crack in tests 11 and 2, respectively, after $20 \mathrm{~km}$ of sliding. Wear grooves, flaking, and some small pitting were observed on both sides of the crack mouth, and their appearance did not alter during the duration of the test. Due to friction force, the opening of the crack mouth was detected at the beginning of the test and was sustained until the end of the test. It is assumed that during sliding, polymer wear debris were trapped and accumulated inside the crack, resulting in progressive opening of the crack. The transfer film formation in pre-cracked tests did not follow the previous trend, as shown in Fig. 8(b). Two parallel transfer film tracks were detected in the direction of sliding. Each of them was about $0.5 \mathrm{~mm}$ in width, and each was separated by a distance of about $1 \mathrm{~mm}$. These tracks became wider as the test progressed, joined, and finally, at the end of running-in period, produced a single track of a width equal to the diameter of the test pin. However, this observation was detected in most of the pre-cracked specimens.

(b) Three surface cracks. Figure 10(a) shows the worn surface in test 3 after $20 \mathrm{~km}$ of sliding. Apparent grooves run across the surface of the wear pin parallel to the sliding direction. Relatively dark and high density wear grooves were observed in the area between the cracks, in addition to openings of the cracks accompanied by trapped wear debris. The transfer film formed by the current wear pin was similar to that in the single imposed-crack tests, consisting of several transfer film marks parallel to the direction of sliding, as shown in Fig. 10(b). On further sliding, the final transfer film completely covered the wear track.

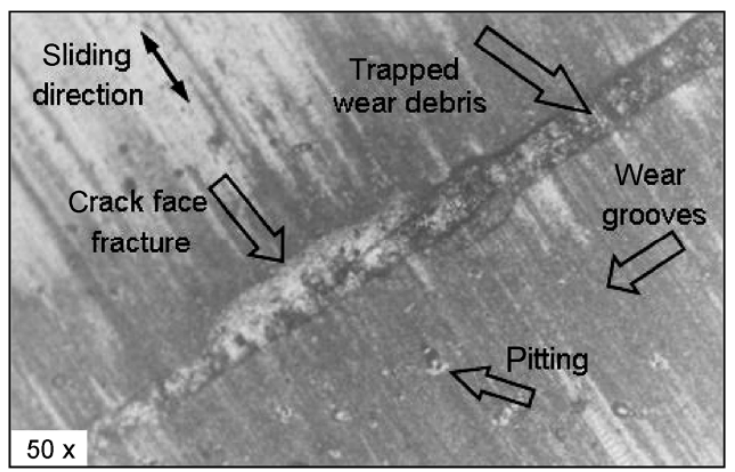

Fig. 9 Optical micrograph of nylon 66 rubbing surface, test 2 after $20 \mathrm{~km}$ sliding, showing trapped wear debris, pitting. 

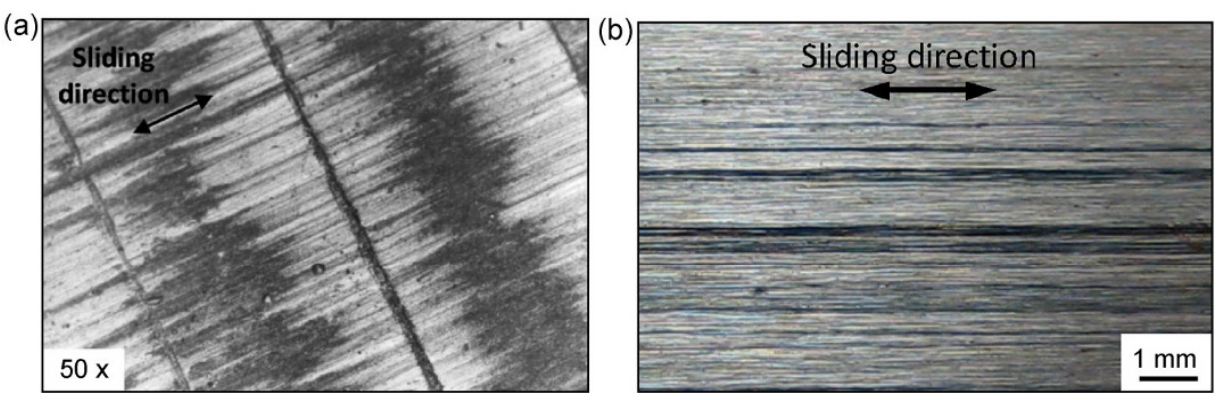

Fig. 10 Optical micrographs of test 3 showing: (a) wear pin surface with high density of wear grooves after $20 \mathrm{~km}$ sliding and (b) steel counterface with transfer film formed after $10 \mathrm{~km}$ sliding.

\section{Wear model}

\subsection{ANN approach}

In the past, the correlations between wear resistance and the characteristic properties of polymers have been interpreted in terms of various semi-empirical equations. Recently, a novel solution has been proposed to better understand the mechanism of wear and analyze the importance of characteristic properties in polymer wear rates. Generally, ANN models operate in the same way as the brain's natural network, using neurons (interconnected nodes) to transfer information. The ANN structure is divided into three segments: input layer, hidden layer, and output layer. The number of neurons in the input and output layers is fixed to the number of input and output variables, whereas the hidden layer can contain more than one layer, depending on its practical application. The greatest advantage of an ANN is its ability to model complex non-linear, multi-dimensional function relationships without any prior assumptions about the nature of the relationships. The network is built directly from experimental data using its self-organizing capability [24]. Figure 11 gives a schematic description of an ANN model configuration. The model is conventionally constructed with three segments: input layer, hidden layer, and output layer. For the convenience of description, the structure of the ANN is expressed as

$$
N_{\text {in }}-\left[N_{1}-N_{2}-\cdots-N_{h}\right]_{h}-N_{\text {out }}
$$

The ANN works as a "black box" where the input vector is imported to the nodes in the output layer, and the results are then expected to export at the output layer through a series of computations in the hidden layer. The learning algorithm is based on a gradient search to optimize the performance function of the network [25]. To obtain optimized NN constructions, the experimental dataset is divided into two parts, one for training and the other for testing the ANN. The training dataset is used to adjust the weights of all connecting nodes until the desired error level is reached. Then the network performance is evaluated on the test dataset, using the coefficient $B$ as a quality measure:

$$
B=1-\frac{\sum_{i=1}^{M}\left(O(P)^{(i)}-O^{(i)}\right)^{2}}{\sum_{i=1}^{M}\left(O^{(i)}-O\right)^{2}}
$$

The coefficient $B$ describes the fit of the ANN output variable curve. Higher $B$ coefficients indicate an ANN with better output approximation capabilities. To avoid any artificial influence in selecting the test data, a random technique was applied in the selection process.

\subsection{ANN dataset and architecture}

Table 3 gives an overview of data used in the present application, which were collected from current and previous studies [21]. The selection of input and output parameters used in the ANN can be expressed as follows.

(a) Applied load (F): We chose this parameter due to its effect on the wear of polymeric materials. It represents the normal applied load $(F)$. It is important to note that the value of $F$ in fluctuating load tests will be the mean value of the load cycle $\left(F_{\text {mean }}\right)$. 


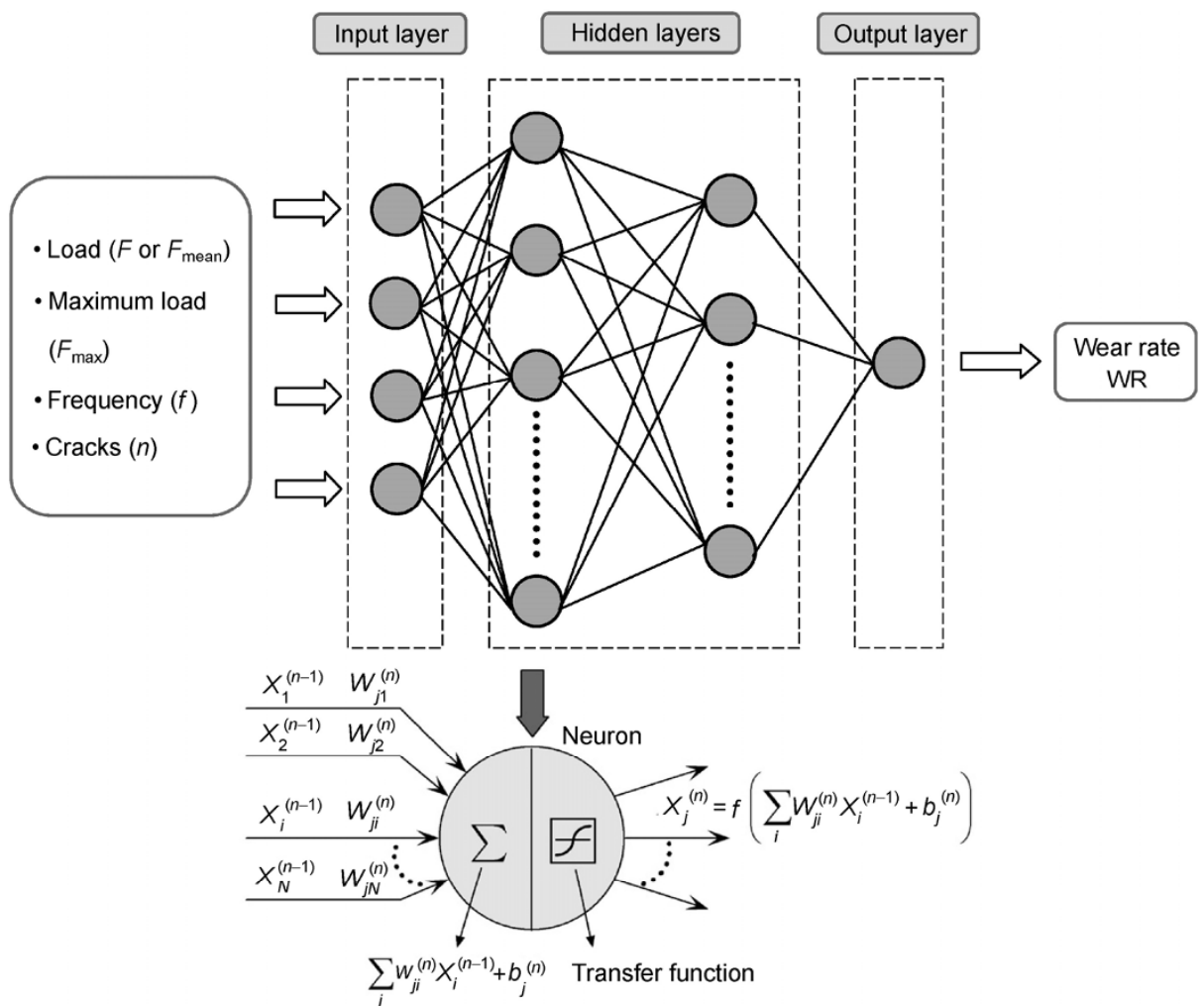

Fig. 11 Schematic description of an ANN configuration.

Table 3 Database, input and output parameters of wear tests

\begin{tabular}{|c|c|c|c|c|c|c|c|c|c|c|c|}
\hline \multirow{2}{*}{$\begin{array}{l}\text { Test } \\
\text { No. }\end{array}$} & \multicolumn{4}{|c|}{ Input } & \multirow{2}{*}{$\frac{\text { Output }}{\mathrm{WR}\left(\times 10^{-4} \mathrm{~mm}^{3} / \mathrm{m}\right)}$} & \multirow{2}{*}{$\begin{array}{l}\text { Test } \\
\text { No. }\end{array}$} & \multicolumn{4}{|c|}{ Input } & \multirow{2}{*}{$\frac{\text { Output }}{\mathrm{WR}\left(\times 10^{-4} \mathrm{~mm}^{3} / \mathrm{m}\right)}$} \\
\hline & $F(\mathrm{~N})$ & $F_{\max }(\mathrm{N})$ & $f(\mathrm{~Hz})$ & $n$ & & & $F(\mathrm{~N})$ & $F_{\max }(\mathrm{N})$ & $f(\mathrm{~Hz})$ & $n$ & \\
\hline 1 & 90 & 90 & 0 & 0 & 13.2 & 14 & 90 & 110 & 1.50 & 1 & 20.4 \\
\hline $2^{*}$ & 90 & 90 & 0 & 1 & 14.8 & 15 & 70 & 135 & 1.50 & 0 & 7.6 \\
\hline 3 & 135 & 135 & 0 & 0 & 18.1 & 16 & 70 & 135 & 1.50 & 0 & 8.5 \\
\hline 4 & 135 & 135 & 0 & 1 & 30.7 & 17 & 70 & 135 & 1.50 & 1 & 23.9 \\
\hline 5 & 90 & 90 & 0 & 3 & 25.2 & 18 & 90 & 110 & 0.75 & 0 & 14.6 \\
\hline 6 & 90 & 170 & 1.50 & 0 & 15.8 & 19 & 90 & 110 & 0.75 & 1 & 15.8 \\
\hline 7 & 90 & 170 & 1.50 & 0 & 22.1 & 20 & 90 & 170 & 0.75 & 0 & 14.7 \\
\hline 8 & 90 & 170 & 1.50 & 1 & 30.1 & 21 & 90 & 170 & 0.75 & 1 & 14.6 \\
\hline 9 & 90 & 135 & 1.50 & 0 & 16 & 22 & 90 & 110 & 0.25 & 0 & 19.8 \\
\hline 10 & 90 & 135 & 1.50 & 0 & 14.7 & 23 & 90 & 110 & 0.25 & 1 & 29.8 \\
\hline $11^{*}$ & 90 & 135 & 1.50 & 1 & 22.4 & 24 & 90 & 170 & 0.25 & 0 & 13.7 \\
\hline 12 & 90 & 110 & 1.50 & 0 & 18.6 & $25^{*}$ & 90 & 170 & 0.25 & 1 & 21.8 \\
\hline 13 & 90 & 110 & 1.50 & 0 & 19.9 & 26 & 90 & 170 & 0.25 & 3 & 29.7 \\
\hline
\end{tabular}

* Data used to test the NN performance

$n$ Number of Imposed surface cracks

(b) Maximum load $\left(F_{\max }\right)$ : We chose this parameter due to its important effect on wear under a fluctuating load that corresponds to maximum loading amplitude $[7,8]$.

(c) Cyclic loading frequency $(f)$ : This parameter is directly related to the time dependent nature of the loading condition. Under a constant loading condition, the value of $f$ will be zero.

(d) Number of surface cracks (n): This parameter is very easy to evaluate in the wear test. Although very 
few tests consider the number of surface cracks, this parameter has a significant effect on wear rate under dry sliding conditions. Also, it is clear that for an uncracked polymer, the value of $n$ will be zero.

The dataset included the testing conditions (load $F$ or $F_{\text {mean }}, F_{\max }$ cyclic frequency, surface cracks) with wear rate $\mathrm{WR}$ as the output parameter. Eighty percent of the data was used for training the model; the remaining $20 \%$ of the dataset was utilized for testing. The maximum number of iterations (epochs) in the training process was 1,000. Five different ANN configurations introduced in previous reports $[17,20$, 21, 24-30] were selected and modified to establish an optimized construction, as shown in Table 4. After multiple trial computations using MATLAB 7.8.0 software, the best topology's $\left\{5-[20-10-10]_{3}-1\right\}$ NN was employed. Figures 12 and 13 show a comparison of the prediction quality for various ANN configurations and the measured and predicted wear rates using the suggested ANN.

\subsection{Wear prediction}

In the previous section, we introduced various neural network configurations and selected the optimal topology. The optimized network was trained using the experimental database mentioned above. Then, the ANN was employed to predict the number of WR values that were not included in the experimental work. Virtual load frequencies $f$ and the number of surface cracks $n$ were used as input parameters and the predicted WRs were the output. Figure 14 shows

Table 4 Configuration of ANNs adopted from literatures.

\begin{tabular}{cccccc}
\hline \multirow{2}{*}{ Reference } & ANN & \multicolumn{3}{c}{ Neurons type } & Training algorithm \\
\cline { 3 - 5 } & & I/P & Hidden & O/P & \\
\hline$[17,24,25]$ & $\left\{9-[15-10-5]_{3}-1\right\}$ & tan-sigmoid & tan-sigmoid & pure-linear & Levenberg-Marquardt algorithm (LM) \\
{$[20,26,27]$} & $\left\{7-[9-3]_{2}-1\right\}$ & tan-sigmoid & tan-sigmoid & pure-linear & Powell-Beale conjugate Gradient algorithm (CGB) \\
{$[21]$} & $\left\{5-[20-10-10]_{3}-1\right\}$ & tan-sigmoid & tan-sigmoid & pure-linear & Levenberg-Marquardt algorithm (LM) \\
{$[28]$} & $\left\{2-[8]_{1}-1\right\}$ & - & tan-sigmoid & pure-linear & Levenberg-Marquardt algorithm (LM) \\
{$[29]$} & $\left\{9-[12-6-3]_{3}-1\right\}$ & - & - & - & Powell-Beale conjugate Gradient algorithm (CGB) \\
{$[30]$} & $\left\{35-[8-5]_{2}-1\right\}$ & tan-sigmoid & pure-linear & pure-linear & Levenberg-Marquardt algorithm (LM) \\
\hline
\end{tabular}

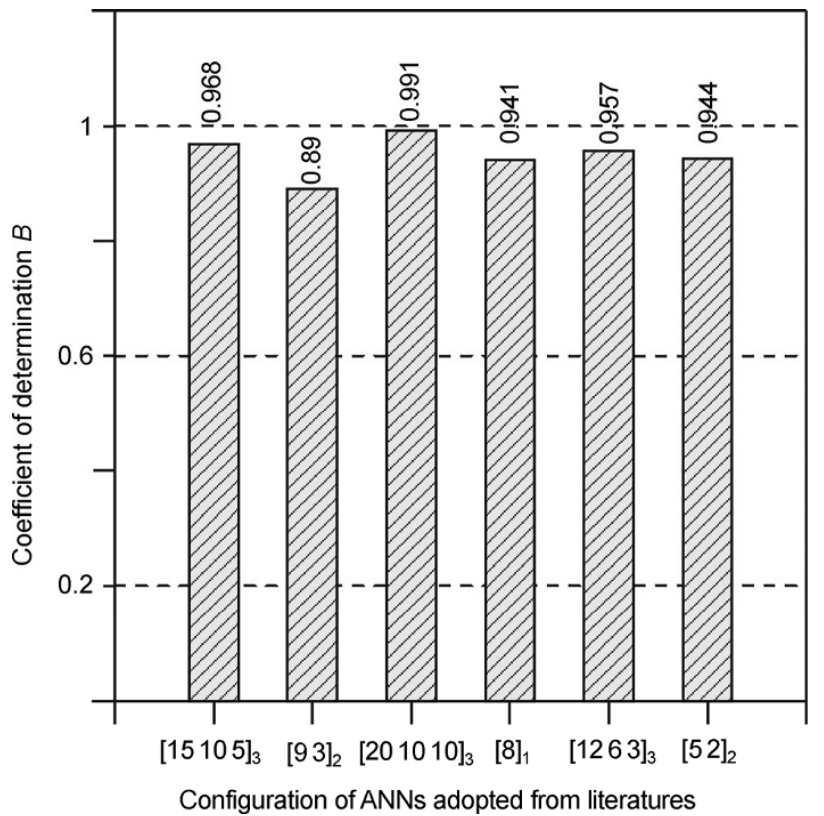

Fig. 12 Comparison of the prediction quality for various $\mathrm{ANN}_{\mathrm{s}}$ configurations.

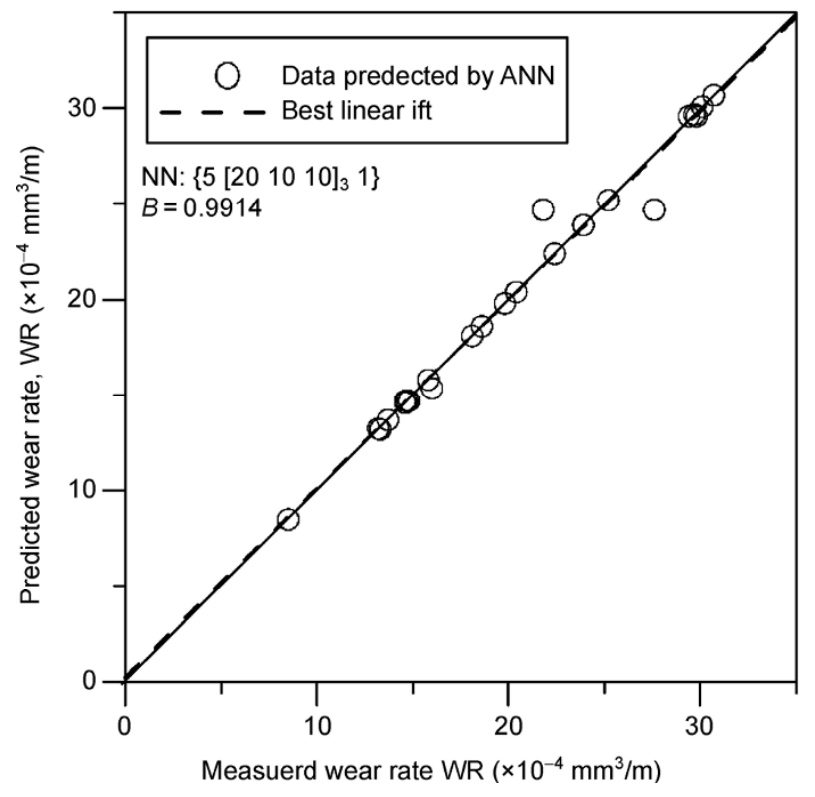

Fig. 13 Determination of the measured and predicted WR of dataset for $[20-10-10]_{3}$ ANN configuration. 


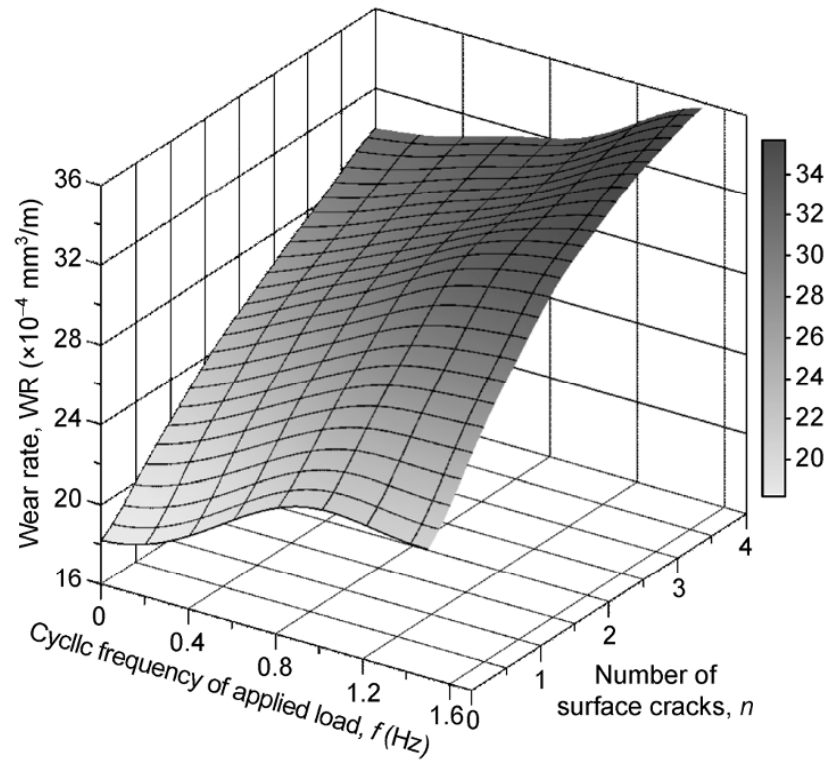

Fig. 14 Prediction for the relationship of wear rate (WR) vs. cyclic frequency of the applied load $(f)$ and number of surface cracks $(n)$.

the predicted 3D profile of the wear rate WR of nylon 66 as a function of $f$ and $n$. The predicted profile demonstrates the dependence of the wear properties on the fluctuation frequency of the applied load as well as the density of surface defects. Predicted wear data shows a good agreement with the measured points.

\section{Discussion}

In earlier studies [10, 31], Dowson attributes the further increase in the polymer wear rate after a certain sliding distance to the appearance of surface cracks, transverse to the direction of sliding, with a suggestion of flaking near these cracks. It was thought that surface deterioration due to fatigue may be encountered after considerable sliding. He believed that the establishment of a polymer transfer film to the steel counterface was of great significance. Moreover, it was suggested that the possible origin of subsurface cracks was necessarily the surface cracks which, at first, propagate at a slight angle from the surface. When these cracks reach the plastically-deformed layer in the subsurface, they then propagate in a direction parallel with the material surface generating the wear debris [32]. However, a likelihood for SFW to occur may effectively also explain the occurrence of high wear rates in polymer-bearing applications subjected to fluctuating loads, rather than to constant loads on laboratory tribometers. Scratches and surface cracks in polymeric parts after service in such applications have been detected and reported in the literature $[5,6]$. Consequently, in our previous study $[7,8]$ we drew attention to the effect of a time-dependent loading system on the accelerating fatigue wear of nylon 66 . Also, it is now well known [33] that surface cracks on a rubbing surface exert a powerful influence on wear behavior. Our results demonstrated that, under both constant and cyclic loads, surface cracks can markedly increase the polymer wear rate. It has further been shown that the number of surface cracks and the frequency of the cyclic load play a dominant role in determining the polymer's increased wear rate. In order to gain a deeper understanding of the results presented in Section 4, we calculated the relative change in wear rate (RCW) due to imposed surface cracks using Eq. (4) and provide a summary of our results in Table 5.

$$
\begin{aligned}
& \text { Relative change in wear rate } \\
& =\frac{\text { wear rate of precracked pin } \mathrm{WR}_{\text {cracked }}}{\text { wear rate of uncracked pin } \mathrm{WR}_{\text {uncracked }}}
\end{aligned}
$$

With a general overview of Table 5 we notice that surface cracks have a considerable effect on nylon 66 wear behavior under constant loads $(\mathrm{RCW}=1.11-1.89)$ while comparatively higher effects were noticed under cyclic loads ( $R C W=1.59-2.17$ ). The frequency $f$ of the cyclic load is also shown to have an effect on wear,

Table 5 Relative change in wear rate due to imposed surface cracks, $F=90 \mathrm{~N}$.

\begin{tabular}{cccc}
\hline Test & $\begin{array}{c}\text { Cyclic } \\
\text { frequency, } \\
f(\mathrm{~Hz})\end{array}$ & $\begin{array}{c}\text { Imposed } \\
\text { surface } \\
\text { cracks }\end{array}$ & $\begin{array}{c}\text { Relative change } \\
\text { in wear rate, } \\
\text { RCW }\end{array}$ \\
\hline 1 & $0^{*}$ & 1 & 1.11 \\
2 & $0^{*}$ & 3 & 1.89 \\
1 & & 1 & 1.59 \\
3 & 0.25 & 3 & 2.17 \\
7 & & & \\
7 & 0.25 & 1 & 1.90 \\
9 & & 3 & \\
10 & 1.50 & & \\
11 & & & \\
\hline
\end{tabular}

* Cyclic frequency $f=0$ represents constant load. 
with a higher RCW value (1.90) found at the higher frequency $f=1.5 \mathrm{~Hz}$.

In our opinion, the imposed surface cracks are considered to be a nucleation of further sub-cracks that nucleate from the original imposed crack and propagate long enough to link up with other subsurface cracks until eventually one crack is large enough to break from the bulk polymer as wear debris. Crack face fractures of the worn surface shown in Fig. 9 support this conclusion. Another finding was that during reciprocating sliding, the friction force acts on the crack mouth, resulting in a crack opening. Polymer wear debris trapped inside this opening volume (Fig. 8(a)) resulted in a sporadic sliding surface, which may well decrease the polymer/metal conformity. Surface grooves found in pre-cracked pins were different from those detected in uncracked pins (Figs.7(a), 8(a), 10(a)), suggesting that the polymer has transferred non-homogeneously to the counterface, and not in a uniform manner as in uncracked pins. Furthermore, an examination of the metallic counterface leads us to the same idea, whereby the transfer film formed by uncracked pins was more uniform and continuous than those formed by single and multi-imposed surface cracks (Figs. 7(b), 8(b), 10(b)). Consequently, relative changes in the wear rate due to surface cracks are expected. These observations agree with those of Furber [10] and Yu [34] who have worked with the same polymer.

We believe that the effect of a surface crack on transfer film formation is not limited to the existence of the surface crack during the initial stage of wear, but may extend to the steady state stage, even if the crack vanishes by wear. The reason is that the polymer's steady state wear rate is influenced by both the surface topography of the metallic counterface and the characteristics of the transfer layer formed after running-in wear [35, 36].

Under fluctuating loads, loading-unloading cycles generate high numbers of subsurface stress regions that increase the tendency for the onset of surface and subsurface cracks. Propagation of these cracks may accelerate the failure and removal of material from the highly strained polymer peaks, hence generally increasing the polymer wear. The observed increase in wear rate for cyclically-loaded polymer pins may be due to the enhanced wear debris escape rate occurring during the unloading phase of the load cycle [5]. Wear will occur during the loaded phase due to the asperity interactions but the debris will be unable to escape due to the high surface conformity, as in the constant load tests. However, during the unloaded phase, the surface conformity decreases, and the debris is then free to escape or be trapped inside the crack volume. Although imposed cracks were designed to be long enough to propagate, almost no crack propagation was detected in wear tests. We suggest that crack propagation in relatively ductile polymers is difficult to detect because of its elastic recovery [37].

Our results, presented in Table 2 and Fig. 15, indicate that the wear rate increases markedly with increasing cyclic frequency. Since the fatigue behavior of a polymer specimen is related to the number of loading and sliding parameters, the variation of one or more of these parameters may affect the polymer's wear behavior. This indicates the need for a greater understanding of the effect of the load frequency on a polymer's mechanical and fatigue properties as well as on wear behavior. At high frequencies, increasing the frequency produces an increase in temperature leading to a degradation in the mechanical properties and decreased fatigue safe-life, while relatively low frequencies have a limited effect on polymer fatigue properties [38]. In contrast to the wear process, the relevant fatigue properties are those in the polymer surface layer which may have been drastically modified during sliding. The dynamic bulk polymer fatigue properties often involve thermal effects attributable to heat build-up within the polymer and are thus very sensitive to the frequency and form of the applied cyclic stress. This suggests that the increase in wear rates found at higher frequency is due to the frequency effect on the fatigue and mechanical characteristics of the bulk polymer. Additionally, its effect on the accelerating propagation of the surface cracks directly leads to an increase in polymer wear. The data in Tables 1 and 2 were used to plot Fig. 16, which represents the relationship between load frequency and the corresponding wear rate for uncracked and cracked specimens. The data for $f=0$ were taken from the constant load test results since there was no load frequency to apply to the polymer. The best fit of the curve shows a linear relationship between the frequency and wear rates and there is a higher 


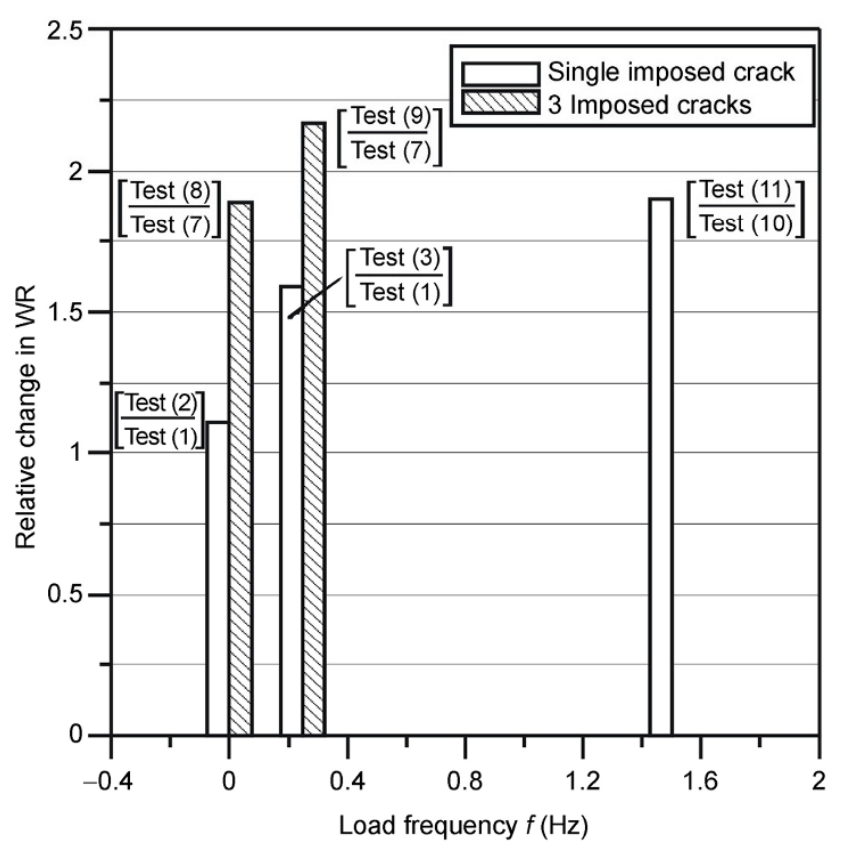

Fig. 15 Relative change in wear rate due to number of imposed surface cracks.

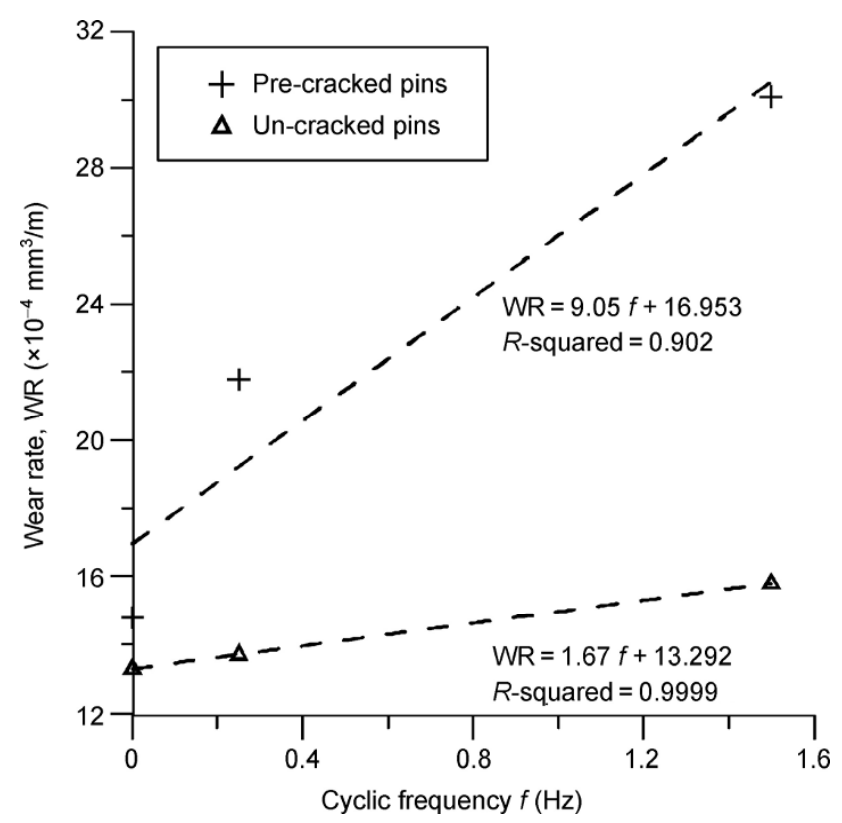

Fig. 16 Variation of nylon 66 wear rates WR with cyclic frequency $f, F=90 \mathrm{~N}$.

tendency for cracked pins with load frequency than uncracked pins. However, these results are not sufficient for performing wear rate regression analysis versus load frequency; more investigations at different frequencies are necessary.

Section B wear has been observed for years by many authors [10, 11, 31, 39] in their investigations of nylon 66 wear and ultra-high-molecular-weight-polyethylene (UHMWPE) sliding against a stainless steel counterface. As mentioned in the introduction, they detected a $10 \%$ to $30 \%$ increase in polymer wear rate after a 120 to $150 \mathrm{~km}$ sliding distance, and suggested that the section B regime is a surface fatigue wear that takes place after a number of cycles to failure proportional to the sliding distance. Interestingly, our tests 6 and 12 results agree qualitatively with their findings, supporting the conclusion that section B is a surface fatigue wear process. A further change of wear rates was attributed to the existence of surface cracks transverse to the wear direction.

Various ANN configurations were applied and their performances calculated using Eq. (3) in order to select the optimum, as shown in Fig. 12. The 5-[20-10-10 $]_{3}-1$ ANN with three hidden layers exhibited better relative performance, $B=0.991$, while the ANNs with single and double hidden layers resulted in lower performance, $B<0.944$. The reason for the lower quality of the simpler ANN configurations is not clear, but we considered that ANNs are inspired by our biological neural system, and a person can learn very quickly and deduce an answer with only a small amount of information available [24]. While simple NNs offer the possibility of fast computing speed with a relatively small training dataset, which may be useful for predicting more simple relationships, our results seem to indicate that in order to accurately describe the complex relationship between the polymer wear rate and chosen input parameters, a more complicated network architecture is required.

The prediction shown in Fig. 14 demonstrates the excellent capability of the selected ANN to prefigure the wear properties of nylon 66 with respect to loading conditions and the existence of surface cracks. In particular, it has become obvious that these conditions have a significant effect on polymer wear resistance. Further increase in the nylon 66 wear rates is observed with a higher frequency of cyclic load and multiple surface cracks.

\section{Conclusions}

Based on our results, we draw the following conclusions from our investigations of the influence of 
load frequency on the wear of pre-existing cracks in a nylon 66 rubbing surface.

(a) Polymer wear was affected by the presence of surface cracks on the nylon 66 rubbing surface. A single transverse crack was shown to be responsible for a significant increase in wear rate. This effect was also found to be sensitive to the nature of the applied load. Under cyclic loads, a surface-cracked polymer showed a marked increase in wear rates than those under constant load.

(b) Wear mechanisms were related to progressive surface fatigue due to the existence of surface cracks, which was affected by cyclic load parameters. The increase in wear rates found at higher frequency was due to its effect on the fatigue and mechanical behavior of the bulk polymer.

(c) Introducing a single transverse crack during the steady state wear phase resulted in the generation of section B wear, characterized by a relatively higher wear rate. This result demonstrates the importance of detecting surface fatigue cracks in a polymer-on-metal bearing configuration, which play a role in increasing the wear of sliding components.

(d) The introduction of ANNs in tribological applications could be beneficial in predicting the wear rate of nylon 66 with respect to loading and the existence of surface cracks without the need to perform too many, long triboexperiments. By introducing load parameters and surface cracks as input data to a suitable ANN, acceptable predicted wear rates may be obtained.

\section{Nomenclature}

\begin{tabular}{|c|c|}
\hline$B$ & coefficient of determination \\
\hline$F$ & applied load, constant load \\
\hline max & $\begin{array}{l}\text { maximum value of the load cycle, cycli } \\
\text { load }\end{array}$ \\
\hline$F_{\text {mean }}$ & mean value of the load cycle, cyclic load \\
\hline & frequency of the load cycle, cyclic load \\
\hline & number of hidden layers \\
\hline$M$ & number of test data \\
\hline$N_{\text {in }}$ & number of input variables \\
\hline$N_{\text {out }}$ & number of output variables \\
\hline$N_{1}, N_{2}, N_{h}$ & $\begin{array}{l}\text { number of neurons in each } h \\
\text { number of artificial surface } c\end{array}$ \\
\hline
\end{tabular}
O
mean value of $O^{(i)}$
$O^{(i)}$
$O(P)^{(i)}$
$\checkmark$
$X$
measured value
the $i^{\text {th }}$ predicted property characteristic
total volume loss by wear
total sliding distance

Open Access: This article is distributed under the terms of the Creative Commons Attribution License which permits any use, distribution, and reproduction in any medium, provided the original author(s) and source are credited.

\section{References}

[1] Hutchings I M. Tribology: Friction and Wear of Engineering Materials. Asterix Press, 1992.

[2] Clark D T, Feast W J. Polymer Surfaces. New York: John Wiley \& Sons, 1978.

[3] Suh N P. The delamination theory of wear. Wear 25: 111-124 (1973)

[4] Chen Y K, Kukureka S N, Hooke C J, Rao M. Surface topography and wear mechanisms in polyamide 66 and its composites. J Mat Sci 35: 1269-1281 (2000)

[5] Barbour P S M, Barton D C, Fisher J. The influence of contact stress on the wear of UHMWPE for total replacement hip prostheses. Wear 181-183: 250-257 (1995)

[6] Cooper J R, Dowson D, Fisher J. Macroscopic and microscopic wear mechanisms in UHMWPE. Wear 162-164: 378-384 (1993)

[7] Abdelbary A, Abouelwafa M N, El Fahham I, Gomaa A I. The influence of cyclic loading parameters on the wear of nylon 66. In Proc. $8^{\text {th }}$ International Conference on Production Engineering and Control PEDAC, Egypt, 2004.

[8] Abdelbary A, Abouelwafa M N, El Fahham I, Gomaa A I. A New reciprocating tribometer for wear testing under different fluctuating loading conditions. Alexandria Eng $J$ 43: 615-619 (2004)

[9] Yap U J, Teoh S H, Chew C L. Effect of cyclic loading on occlusal contact area wear of composite restoratives. Dent Mater 18: 149-158 (2002)

[10] Furber K, Atkenson J R, Dowson D. The mechanisms for nylon 66: Paper II. In Proc. of the 3rd Leeds-Lyon Symposium on Tribology, 1976.

[11] Atkinson J R, Brown K J, Dowson D. The wear of high molecular weight polyethlene. Part I: The wear of isotropic polyethylene against dry stainless steel in unidirectional motion. J Lub Tech 100: 208-218 (1978) 
[12] Anderson J C, Robins E J. The influence of temperature generation on the wear of some polymers. In Proc. of the 3rd Leeds-Lyon Symposium on Tribology, 1976.

[13] Frangu L, Ripa M. Artificial neural networks applications in tribology-A survey. In 2001 NATO Advanced Study Institute on Neural Networks for Instrumentation, Measurement, and Related Industrial Applications: Study Cases, Crema, Italy, 2001: 35-42.

[14] Rutherford K L, Hatto P W, Davies C, Hutchings I M. Abrasive wear resistance of $\mathrm{TiN} / \mathrm{NbN}$ multi-layers: Measurement and neural network modelling. Surf Coat Tech 86-87: 472-479 (1996)

[15] Jones S P, Jansen R, Fusaro R L. Preliminary investigations of neural network techniques to predict tribological properties. Tribol Trans 40: 312-320 (1997)

[16] Velten K, Reinicke R, Friedrich K. Wear volume prediction with artificial neural networks. Tribol Int 33: 731-736 (2000)

[17] Zhang Z, Friedrich K. Artificial neural networks applied to polymer composites: A review. Comp Sci Tech 63: 20292044 (2003)

[18] Zhu J, Shi Y, Feng X, Wang H, Lu X. Prediction on tribological properties of carbon fiber and $\mathrm{TiO}_{2}$ synergistic reinforced polytetrafluoroethylene composites with artificial neural networks. Mater Des 30: 1042-1049 (2009)

[19] Kranthi G, Satapathy A. Evaluation and prediction of wear response of pine wood dust filled epoxy composites using neural computation. Comp Mater Sci 49: 609-614 (2010)

[20] Lada A, Friedrich K. Artificial neural networks for predicting sliding friction and wear properties of polyphenylene sulfide composites. Tribol Int 44: 603-609 (2011)

[21] Abdelbary A, Abouelwafa M N, El Fahham I, Hamdy A H. Modeling the wear of Polyamide 66 using artificial neural network. Mater Des 41: 460-469 (2012)

[22] Goto K, Kagawa Y, Nojima K, Iba H. Effect of crack fibre interactions on crack growth rate in fibre-reinforced brittle matrix composite under cyclic loading. Mater Sci Eng A212: 69-74 (1996)

[23] Abdelbary A, Abouelwafa M N, El Fahham I, Hamdy A H. The influence of surface crack on the wear behaviour of polyamide 66 under dry sliding condition. Wear 271: 2234-2241 (2011)

[24] Zang Z, Friedrich K, Velten K. Prediction on tribological properties of short fibre composites using artificial neural networks. Wear 252: 668-675 (2002)

[25] Jiang Z, Zhang Z, Friedrich K. Prediction on wear properties of polymer composites with artificial neural network. Comp Sci Tech 67: 168-176 (2007)

[26] Lada A, Gyurova L A, Minino P, Schlorb A K. Modeling the sliding wear and friction properties of polyphenylene sulfide composites using artificial neural networks. Wear 268: 708-714 (2010)

[27] Jiang Z, Gyurova L A, Schlarb A K, Friedrich K, Zhang Z. Study on friction and wear behavior of polyphenylene sulfide composites reinforced by short carbon fibers and sub-micro $\mathrm{TiO}_{2}$ particles. Comp Sci Tech 68: 734-742 (2008)

[28] Liu X, Davim P, Cardoso R. Prediction on tribological behaviour of composite PEFK-CF30 using artificial neural networks. J Mat Proc Tech 189: 374-378 (2007)

[29] Jiang Z, Gyurova L, Zhang Z, Friedrich K, Schlarb K. Neural networks based prediction on mechanical and wear properties of short fibers reinforced polyamide composites. Mater Des 29: 628-637 (2008)

[30] Helmy A. Neural network wear prediction models for the polymethylmethacrylate PMMA. Alexandria Eng $J$ 43: 401-407 (2004)

[31] Dowson J R, Atkinson K, Brown K. The wear of high molecular weight polyethylene with particular reference to its use in artificial human joints. In Advances in Polymeric Function and Wear, Vol. 5B, Lee L H Ed. New York: Plenum Press, 1976: 533-551.

[32] Terheci M. Microscopic investigation on the origin of wear by surface fatigue in dry sliding. Mater Char 45: 1-15 (2000)

[33] Fam H, Keer L M, Chang W, Cheng H S. Competition between fatigue crack propagation and wear. $J$ Tribol 115 : 141-145 (1993)

[34] Yu S R, Hu H X, Zhang Y, Liu Y H. Effect of transfer film on tribological behavior of polyamide 66-based binary and ternary nanocomposites. Polym Int 57: 454-462 (2008)

[35] Zalisz Z, Vroegop P H, Bosma R. A running-in model for the reciprocating sliding of nylon 6.6 against stainless steel. Wear 121: 71-93 (1988)

[36] Franklin S E, de Kraker A. Investigation of counterface surface topography effect on the wear and transfer behaviour of a POM-20\%PTFE composite. Wear 225: 766-773 (2003)

[37] Lamethe J F, Sergot P, Chateauminois A, Briscoe B J. Contact fatigue behaviour of glassy polymers with improved toughness under fretting wear conditions. Wear 255: 758-765 (2003)

[38] Osgood C C. Fatigue Design. Pergamon Press, 1970.

[39] Brown K J, Atkinson J R, Dowson D. The wear of UHMWPE: Part II. J Lub Tech 104: 17-22 (1982) 


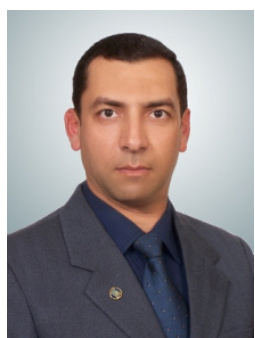

Ahmed ABDELBARY. He has received his BS degree in the Mechanical Engineering from Military Technical College in Cairo, MS and PhD degree from Alexandria University, Egypt. He has an academic research experience in wear of polymers since 1999. He is a full member of the Egyptian Society of Tribology EGTRIB. His areas of technical expertise extend to design and manufacture of many mechanical systems. He has published several research papers on tribology of polymers, in well-reputed engineering journals. 